\title{
Natural course of diffuse large B cell lymphoma-a manifestation in buccal mucosa
}

\author{
Nishant Batta ${ }^{1,2}$, Mridula Shukla $^{1,2}$ and Manoj Pandey ${ }^{1,2^{*}}$ (D)
}

\begin{abstract}
Background: Transformation and progression of lymphoma after treatment is well known; however, since the advent of chemotherapy and radiotherapy, progression in untreated lymphoma is seldom seen. We present a case which was misdiagnosed and treated as abdominal tuberculosis later presented with progression and involvement of oral cavity.

Case presentation: A 41-year-old male who presented with urinary symptoms and abdominal pain was diagnosed as abdominal tuberculosis and treated. Two years later, he presented with B symptoms and oral cavity lesion that was diagnosed as diffuse large B cell lymphoma. The patient was treated with R-CHOP chemotherapy with complete regression of the lesion.

Conclusion: Involvement of extranodal sites in predominantly nodal disease does occur; however, involvement of oral cavity is rare. Though primary extranodal lymphoma is reported to occur in oral cavity and oropharynx, natural progression in untreated disease is seldom documented.
\end{abstract}

Keywords: Lymphoma, B cell, Large cell, Tuberculosis, Buccal mucosa, Alveolus

\section{Introduction}

Involvement of oral cavity in lymphoma is rare, having a reported incidence of extranodal involvement in $2-5 \%$ cases [1]. It is non-Hodgkin's lymphoma (NHL) which is having more extra nodal spread than Hodgkin's lymphoma. Extra nodal NHL sites can be GIT, CNS, skin, bone etc., out of which oral cavity as a primary site of extra nodal lymphoma is even rarer [2,3]. Most of the ulceroproliferative growths in oral cavity in India are squamous cell cancers. There is lack of data reported on the natural course of disease in lymphomas, with only a few reported cases as a primary extra nodal lymphoma in oral cavity sites-tongue, buccal mucosa, and masticator muscles [4]. With this case report, the natural course of diffuse large B cell lymphoma (DLBCL) with the clinical, radiological, and histopathological findings are being discussed as a manifestation in the oral cavity.

\footnotetext{
* Correspondence: manojpandey66@gmail.com

${ }^{1}$ Department of Surgical Oncology, Institute of Medical Sciences, Banaras Hindu University, Varanasi 221005, India

${ }^{2}$ SRL Diagnostics, Lanka, Varanasi, India
}

\section{Case report}

A 41-year-old male presented to the urology OPD in September 2014 with complaints of colicky pain in the right flank and dysuria of 3 months duration. Examination revealed right renal angle tenderness. The renal function was normal, and an ultrasonography revealed $2.3 \times 1.5 \mathrm{~cm}$ renal abscess, $1.5 \mathrm{~cm}$ left calyceal cyst, 2.8 $\mathrm{mm}$ right renal calculus, with a normal bladder, and post-void residual urine (PVRU) of $16 \mathrm{ml}$. A mild splenomegaly $(13 \mathrm{~cm})$, with multiple enlarged lymph nodes in periumbilical region, largest measuring $20 \times 19$ $\mathrm{mm}$, was also identified; there were no other nodes and no free fluid in the abdomen. A FNAC from lymph nodes was performed which was inconclusive; however, a clinical diagnosis of tuberculosis was made and the patient was started on antitubercular treatment.

The patient completed the prescribed antitubercular treatment and remained asymptomatic for 2 years. No follow-up scans were done. In October 2016, the patient again presented to the urology OPD with complaint of recurrent pain in the right flank for 10 days. The pain was moderate in intensity, radiating to the back along

(c) The Author(s). 2019 Open Access This article is distributed under the terms of the Creative Commons Attribution 4.0 International License (http://creativecommons.org/licenses/by/4.0/), which permits unrestricted use, distribution, and 
with high-grade fever with rigors. There were no urinary complaints this time. Abdominal examination was normal, the renal function was normal, no scans were done, and the patient was referred to orthopedics for treatment of back pain, wherein symptomatic treatment was given. In November 2016, the patient presented to the surgical oncology OPD with complaints of painless progressive ulceroproliferative lesion in the oral cavity, fever, and abdominal pain. On examination of the oral cavity, there was a grayishbrown ulcerative growth starting from the first premolar and continuing till retro molar trigone (RMT) region, involving the right lower gingivobuccal sulcus (GBS), alveolus, and floor of mouth (Fig. 1). Level Ib lymph nodes were palpable in the right neck. The abdominal examination revealed a hard mass in the umbilical and another in the left lumber area with welldefined borders and limited mobility in the lumber mass while the paraumbilical mass was mobile. There were no other significant findings on abdominal and systemic examination.

The CECT of the oral cavity and neck was performed that showed ill-defined thickening in the right inferior gingiva buccal sulcus (premolar and molar region), buccal mucosa, and RMT measuring approximately $54 \times 30 \times 19 \mathrm{~mm}$; the mass was seen infiltrating the masseter muscle, and destruction of the right inferior alveolus in the molar region and floor of mouth medially was also noted (Fig. 2). Multiple subcentimeter neck nodes level I and II were seen in the CT scan with the largest of size $25 \times 18 \mathrm{~mm}$ in the right submandibular region.

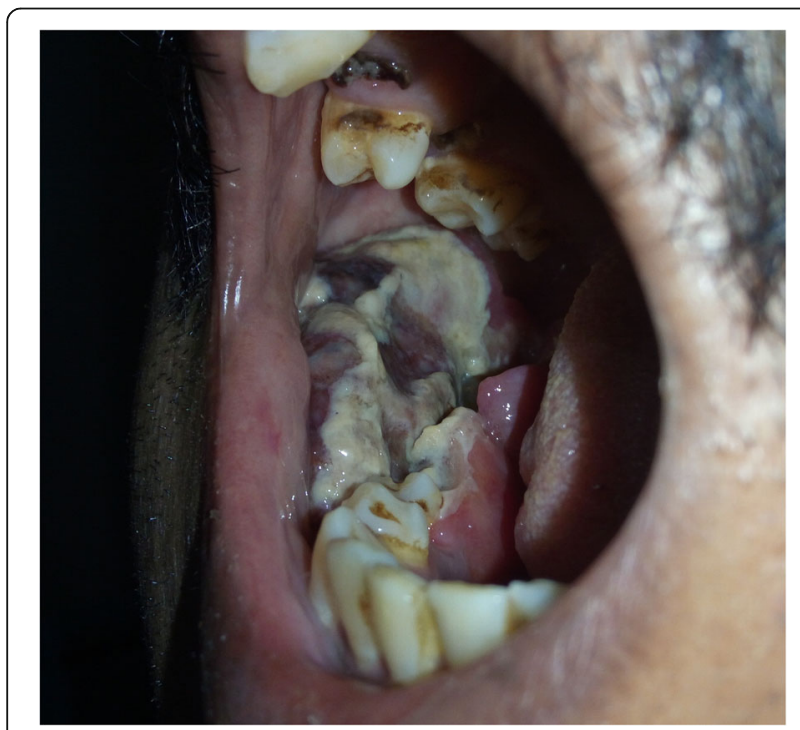

Fig. 1 Clinical photograph showing the slough covered, flashy, ulceroproliferative lesion in the buccal mucosa with involvement of alveolus and extension on to right floor of mouth
Abdominal CECT showed a matted lymph node mass in the mesentery of the small bowel and another well-defined mass lesion just posterior to the spleen and superior to the left kidney. The left adrenal was not identified separately (Fig. 3).

A punch biopsy was taken from the right buccal mucosal lesion that showed features suggestive of round cell tumor (Fig. 4). The IHC was performed that showed positivity for CD45, CD 20, CD 10 (immunoreactive score of $4+$ ), and bcl-2 (immunoreactive score of 2+) (Fig. 4). The KI-67 showed immunoreactive score $4+$ in $>90 \%$ cells (Fig. 5). The CD3, CD 138, CD 99, ALK-1, CK, chromogranin A, desmin, and HMB-45 were negative (Fig. 6). The morphological and IHC features a diagnosis of diffuse large B cell lymphoma (DLBCL). The patient was started on $\mathrm{R}-\mathrm{CHOP}$ regime and had complete response with regression of the disease after 6 cycles. He continued on maintenance therapy for 1 year and is alive and disease free 14 months after completion of the treatment and stoppage of maintenance therapy.

\section{Discussion}

Non-Hodgkin's lymphoma of B cell lineage is the third most common malignant lesion in the oral cavity and maxillofacial region. The oral cavity, including the palate, gingiva, tongue, buccal mucosa, floor of mouth, and lips, is the primary site of approximately $2 \%$ of extranodal NHL. Waldeyer's ring is the most frequently involved site, being second only to the GIT in extranodal NHL. Involvement of the muscles and bone is rare in primary extranodal lymphomas [5-7]. Non-immunosuppressed patients of any age can be affected, most patients being in middle age group or older adult, with male preponderance. The most common clinical appearance of NHL in the mouth is a non-healing, painless ulcer [8-10].

Patients with disseminated disease course and the presence of an immunosuppressed condition like AIDS have poor prognosis. EBV and HHV-8 have also been reported to accelerate the process in immunosuppressed patients causing PBL which is a subtype of DLBCL [11].

Since the differentials of an oral lesion are manifold, it becomes mandatory to device good diagnostic methods and representations. Though the morphology of the lesions is different from squamous carcinoma, the spindle cell variant of squamous carcinoma, soft tissue tumors, and melanoma have to be considered as differential diagnosis. Imaging is important for staging the disease, even though it may not have any diagnostic importance as there are no local specific features to suggest a diagnosis of lymphoma. IHC remains the cornerstone of confirmation of diagnosis in such patients. Lymphomas respond very well to 


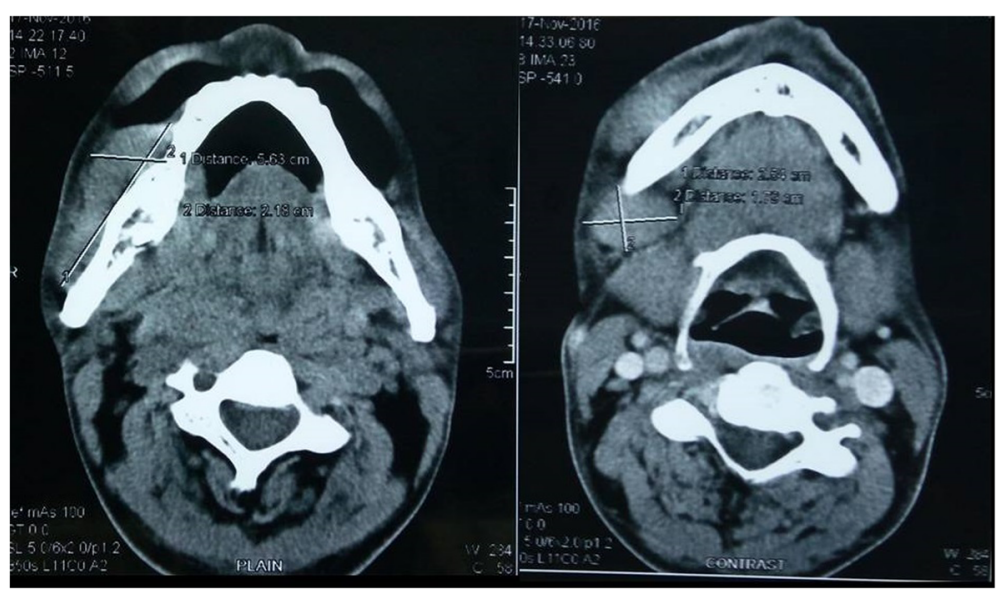

Fig. 2 CT scan of the face and neck (Left) showing the lesion in the right buccal mucosa with extension onto the floor of the mouth and destruction of mandible (Right) showing the node in level lb neck

chemotherapy, with lesions starting to shrink with the first cycle itself. Hence, inadvertent dental procedures and mutilating surgeries should be avoided especially in patients with disease elsewhere like in the present case and also in cases where there are isolated oral lesions.

There have been a number of case control studies that have found association of chronic infections with lymphoma $[12,13]$. The full discussion on the subject is beyond the scope of this study; however, the standard incidence ratio (SIR) has been reported to be ranging from 1.3 to 2.4. The SIR increases with the increase in time since exposure.

As most of the lymphomas are diagnosed and treated at an early stage, it is rare to find cases that demonstrate the natural history of untreated lymphoma.

\section{Conclusions}

Extranodal involvement of the buccal mucosa as part of the natural progression in untreated predominantly nodal lymphoma is never reported before. In patients with oral lesions that have round cell histology, lymphoma should be considered as differential diagnosis. A careful history, radiology, and immunohistochemistry clinches the diagnosis.

\section{Learning points}

Fine needle aspiration cytology is not a reliable investigation in intraabdominal lymphadenopathy.

An inconclusive FNAC should not be taken as negative for malignancy and repeat cytology, and biopsy should be considered.

Tuberculosis should not be the only diagnosis in intraabdominal lymphadenopathy, and other causes of lymphadenopathy should always be considered.

Antitubercular treatment should not be started till the diagnosis of tuberculosis is confirmed with demonstration of AFB or by TB PCR.

Lymphoma responds very well to chemotherapy, and surgery should not be considered as treatment till the lymphoma has been ruled out.

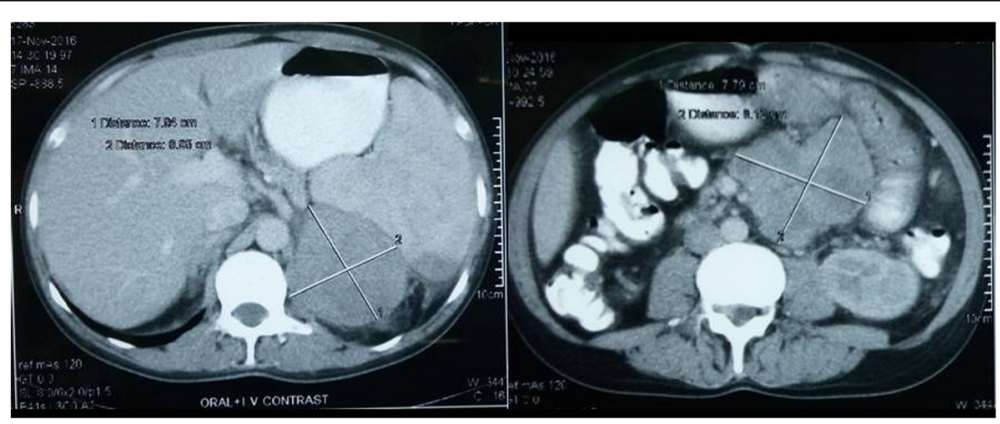

Fig. 3 Contrast-enhanced CT scan of the abdomen (Left) showing lesion in the left upper abdomen posterior to the spleen and superior to the left kidney (right) showing matted mass in small bowel mesentery 


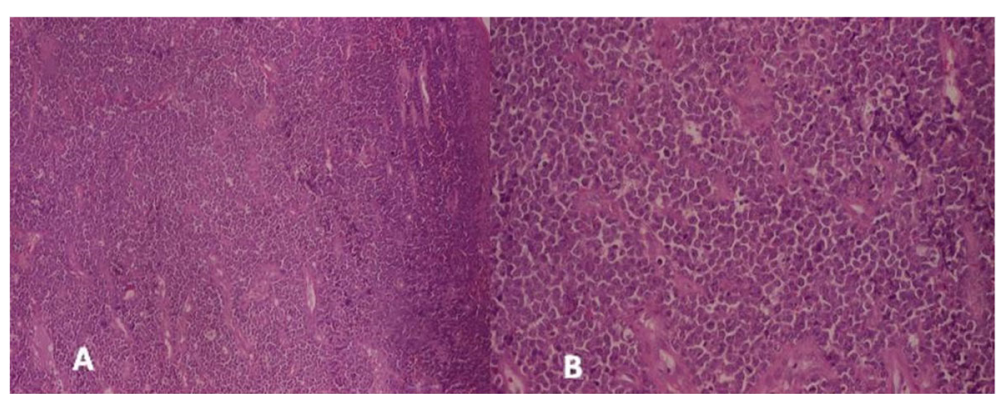

Fig. 4 Photomicrograph showing round cell neoplasm. a H\&E $\times 40$ and $\mathbf{b} H \& E \times 100$

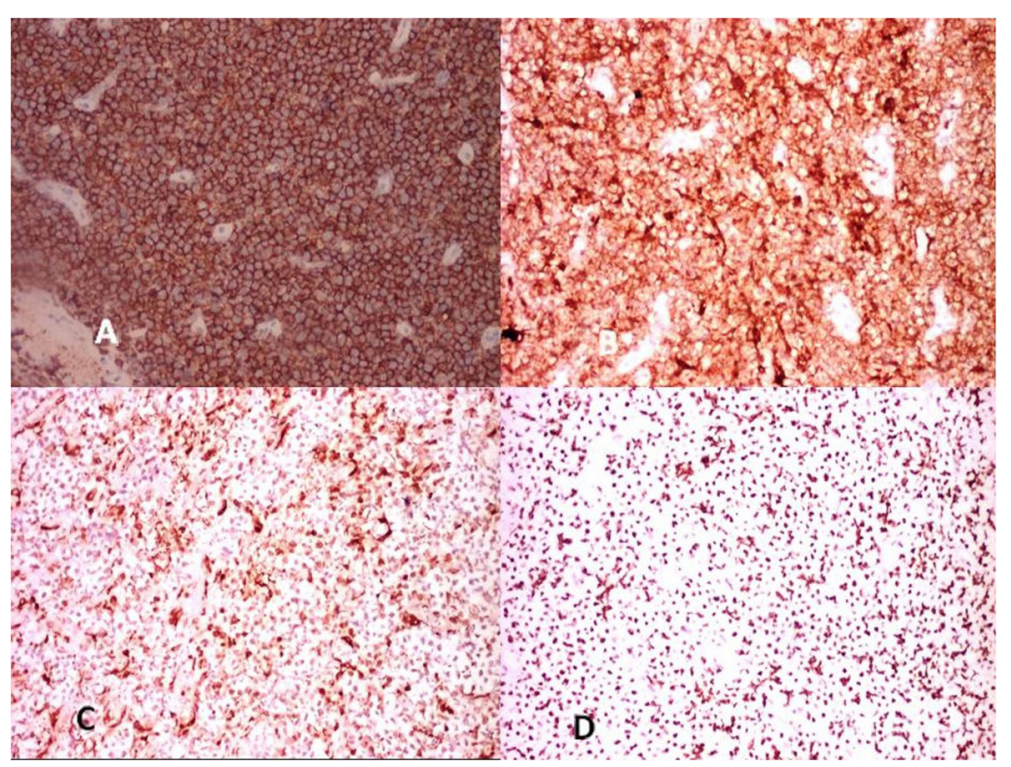

Fig. 5 Photomicrograph showing positive staining for a CD20 ×40, b CD $10 \times 40, \mathbf{c} B C L 2 \times 40$, and $\mathbf{d} \mathrm{Ki}-67 \times 40$

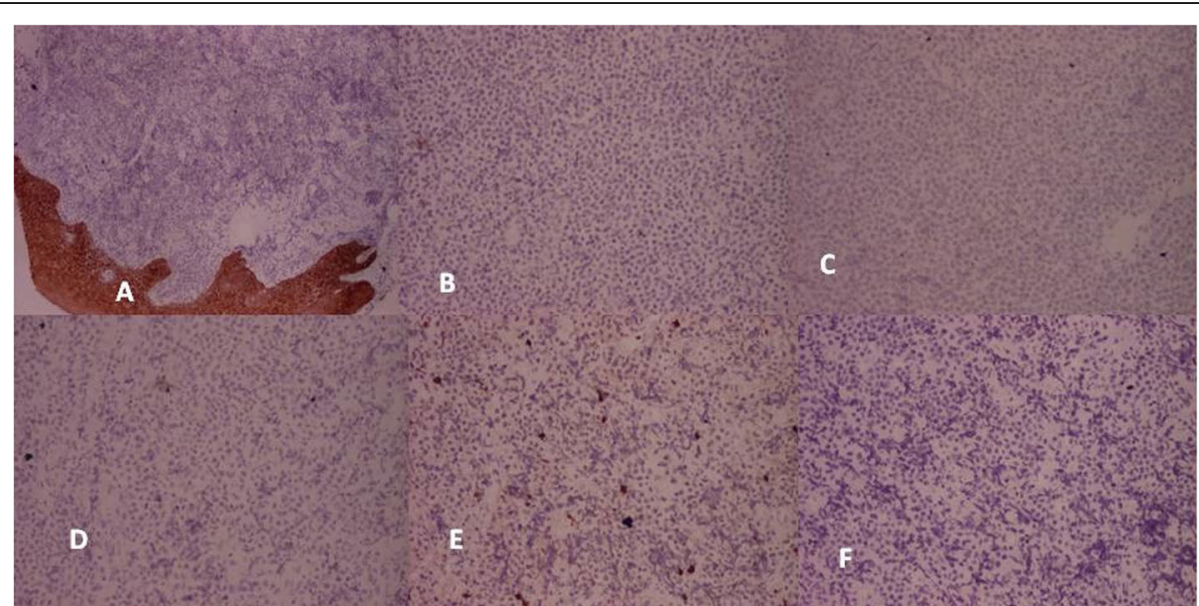

Fig. 6 Photomicrograph showing negative staining for a cytokeratin $\times 40$, b desmin $\times 40$, c HMB $45 \times 40$, d ALK1 $\times 40$, e CD3 $\times 40$, and $\mathbf{f}$ CD $99 \times 40$ 


\section{Acknowledgements}

None

\section{Authors' contributions}

NB did the literature search, collected the data, and prepared the manuscript. MS contributed to the writing of pathological part of the manuscript and interpretation of IHC. MP conceived and designed and edited the final manuscript for publication. All authors read and approved the final manuscript.

\section{Funding}

No financial support

\section{Availability of data and materials}

All the data has been used in this manuscript, and there is no additional data.

\section{Ethics approval and consent to participate}

Not applicable

\section{Consent for publication}

Written informed consent was obtained from the patient for publication of this case and accompanied images.

\section{Competing interests}

The authors declare that they have no competing interests.

Received: 22 September 2019 Accepted: 2 December 2019

Published online: 16 December 2019

\section{References}

1. Soderholm AL, Lindqvist C, Heikinheimo K, Forssell K, Happonen RI. NonHodgkin's lymphomas presenting through oral symptoms. Int J Ora Maxillofac Surg. 1990:19:131-4.

2. Zanakis SN, Kambas I, Gourlas PG. A non-Hodgkin's lymphoma in the buccal mucosa. A case report. Oral Surg Oral Med Oral Pathol. 1992;74:340-2.

3. Gusenbauer A, Katsikeris NF, Brown A. Primary lymphoma of the mandible: report of a case. J Oral Maxillofac Surg. 1990;43:409-15.

4. Barber HD, Stewart JCB, Baxter WD. Non-Hodgkin's lymphoma involving the inferior alveolar canal and mental foramen: report of a case. J Oral Maxillofac Surg. 1992:50:1334-6.

5. Ceysens $C$, Horvath M, Termite JL, Lemahieu SF. Extranodal non-Hodgkins lymphoma of the head and neck presenting as mandibular swelling: report of two cases. J Belg Radiol. 1992;75:37-9.

6. Chong J, Som PM, Silvers AR, Dalton JF. Extranodal non-Hodgkins lymphoma involving the muscles of mastication. Am J Neuroradiol. 1998;19: 1849-51.

7. Harnsberger RH, Bragg DG, Osborn AG, Smoker WR, Dillon WP, Davis RK, et al. Non-Hodgkins lymphoma of head and neck: CT evaluation of nodal and extranodal sites. Am J Roentgenol. 1987;149:785-91.

8. Kemp S, et al. Oral non-Hodgkin's lymphoma: review of the literature and World Health Organization classification with reference to 40 cases. Oral surg Oral med Oral Pathol Oral Radiol Endod. 2008;105(2):194-201.

9. Epstein JB, Epstein JD, Le NDGorsky M. Characteristics of oral and paraoral malignant lymphoma: a population-based review of 361 cases. Oral Surg Oral Med Oral Pathol Oral Radiol Endod. 2001:92(5):519-25.

10. Corti $\mathrm{M}$, et al. Primary extranodal non-Hodgkin lymphoma of the head and neck in patients with acquired immunodeficiency syndrome: a clinicopathologic study of 24 patients in a single hospital of infectious diseases in Argentina. Int Arch Otorhinolaryngol. 2015;19(4):354-8.

11. Corti $\mathrm{M}$, et al. Plasmablastic lymphoma of the oral cavity: an aggressive subtype of lymphoma strongly associated with the human immunodeficiency virus infection. J J Otolaryn. 2015:1:1-5.

12. Tavani A, La Vecchia C, Franceschi S, Serraino D, Carbone A. Medical history and risk of Hodgkin's and non-Hodgkin's lymphomas. Eur J Cancer Prev. 2000;9:59-64.

13. Askling J, Ekbom A. Risk of non-Hodgkin's lymphoma following tuberculosis. Br J Cancer. 2001;84:113-5. https://doi.org/10.1054/bjoc.2000.1551.

\section{Publisher's Note}

Springer Nature remains neutral with regard to jurisdictional claims in published maps and institutional affiliations.
Ready to submit your research? Choose BMC and benefit from:

- fast, convenient online submission

- thorough peer review by experienced researchers in your field

- rapid publication on acceptance

- support for research data, including large and complex data types

- gold Open Access which fosters wider collaboration and increased citations

- maximum visibility for your research: over $100 \mathrm{M}$ website views per year

At $\mathrm{BMC}$, research is always in progress.

Learn more biomedcentral.com/submissions 